\title{
Travel Time Variability After a Shock: THE CASe of THE Twin Cities RAMP Meter ShUt OFF
}

David Levinson ${ }^{1}$, Lei Zhang ${ }^{2}$

University of Minnesota Department of Civil Engineering, 500 Pillsbury Drive SE, Minneapolis, MN 55455 USA Voice: (612) 625-6354 Fax (612) 626-7750 levin031@tc.umn.edu

1. Assistant Professor, 2. Research Assistant

Draft Nov.28, 2001

\begin{abstract}
Ramp meters in the Twin Cities were turned off for 8 weeks in the Fall of 2000. This paper analyzes traffic data collected in this experiment on travel time variability with and without ramp metering for several representative freeways during the afternoon peak period. Travel time variability is generally reduced with metering. However, it is found that ramp meters are particularly helpful for long trips relative to short trips. The annual benefits from reducing travel time variability with meters are estimated to be \$33.1 million, compared to the annual ramp metering costs of \$2.6 million in the Twin Cities metro area. Thus, the impact on travel time variability should be captured in future ramp metering benefit/cost analysis.
\end{abstract}

Key words: Freeway Operations, Ramp Meters, Travel Time Variability, Travel Time Reliability 


\section{INTRODUCTION}

Ramp meters have been depicted as ITS devices being able to prevent freeway breakdown and hence maximize the throughput at freeway bottlenecks. Reduced travel delay, improved safety, fuel consumption savings and emission reduction are reported frequently by researchers and practitioners after deployment of ramp metering systems (e.g. Kang and Gillen, 1999). It is well recognized that ramp metering decreases the variability of freeway travel speed and so the freeways become more reliable. However, the additional delay at on-ramps increases the overall trip travel time variability. Therefore, whether ramp metering makes travel more reliable is not clear under these two opposite forces. Previous benefit/cost studies on ramp metering are unable to take travel reliability change into account because of a lack of both theoretical and empirical work in the field. As reported by many researchers (Banks, 1991; Hall and Agyemang-Duah, 1991; Persaud and Hurdle, 1991; Cassidy and Bertini, 1999), the reduced freeway capacity after breakdown ranges from $0 \%$ to $8 \%$. A majority of papers conclude that the capacity reduction when queue is present is negligible. Thus the importance of meters may not lie in reducing total travel time, as it mostly just shifts the time from freeways to meters. Rather it could be in reducing the variability in travel time by taking noise out of the system. If ramp metering does improve travel reliability, the benefits resulting from it should be considered.

In what may be the single most comprehensive experiment in the history of surface transportation, ramp meters in the Twin Cities of Minneapolis and St. Paul were the subject of a recent test of their effectiveness. By turning the meters off for 8 weeks in October, November, and December 2000, it has been possible to determine the effects of ramp metering on travel times and travel time variability. This paper presents the detailed results of an analysis of observed data on several representative freeways, I494 outer loop (eastbound and southbound), I494 inner loop (westbound and northbound), TH169 northbound and TH62 westbound (see Figure 1 for study freeway locations), during the afternoon peak period, and considers travel time variability with and without ramp meters to control freeway traffic in the Twin Cities area.

The first ramp meter was installed in the Twin Cities in 1970 on southbound I- 35E north of downtown Saint Paul. Now after 30 years of evolution, meters are standard on many freeways. There are currently 443 meters regulating ramps throughout the metropolitan area. Since the first installation of ramp meters, which operated as an isolated system, there has been sustained improvement in the system. Now most of the ramp meters are controlled centrally in real-time. Also, initially there were single lane ramp meters, but to better utilize the system so that it does not affect the arterial 
or connecting roads, the usual practice now is to have two-lane ramp meters, which increase the storage capacity of ramps. Ramp meters in the Twin Cities were intended "to optimise flow in metro area freeway corridors by making efficient use of available transportation facilities" (Mn/DOT 1996a). The Minnesota Department of Transportation made this goal operational through a control strategy that divided freeways into zones terminating at bottlenecks. The number of vehicles in each zone at a given time was constrained by the capacity of the bottleneck. Ramp metering was used to limit those vehicles. The metering zone equation can be expressed as:

$$
A+U+M+F=X+B+S
$$

s.t. incident override and occupancy override

Where:

A upstream mainline volume (measured variable);

$U \quad$ sum of unmetered entrance ramp volumes (measured variable);

$M \quad$ sum of metered local access ramp volumes (controlled variable);

$F \quad$ sum of metered freeway-to-freeway access ramp volumes (controlled);

$X \quad$ sum of exit ramp volumes (measured variable);

$B \quad$ downstream bottleneck volume at capacity (constant);

$S \quad$ space available within the zone (computed from measured variables).

(For more details on the Minnesota algorithm, interested readers may refer to (Bogenberger and May, 1999) and (Mn/DOT 1998)).

Controversy arose when a State Senator from rural Minnesota challenged the strategy of the state Department of Transportation. The long delays at some ramps (at times, though not generally, in excess of 20 minutes), designed to ensure that the freeway remained free-flowing, drew the ire of some commuters, who believed the system was at best inefficiently managed. The state legislature passed a bill in Spring 2000 requiring a ramp meter shut off experiment. This paper is an analysis of data collected with and without metering.

The next section details how data were chosen from raw volume and occupancy counts collected by inductive loop detectors with the aim that impacts on travel time from factors other than ramp meters can be minimized. The following section shows the method used to measure travel times on ramps and freeway segments from the data available. Then inter-day and intra-day travel time variability are defined for this case study and results of variability with and without ramp metering control are shown and discussed. Recommendations and conclusions are delivered at the end of this paper. 


\section{DATA}

Data were collected on six representative freeway sections in workday PM peaks (14:30 to 19:00 pm). These sections are: I494 outer loop (eastbound and southbound), I494 inner loop (westbound and northbound), TH169 northbound and TH62 westbound. We followed two criterion in selecting freeway sections and the study period:

- The time space domain must be free of congestion at the beginning and end of study. The flow conditions within those freeway sections will not be affected by further downstream queues.

- Data must be complete. There is no idle detector in the studied freeway sections.

We expect that ramp meters affect freeway travel time reliability. However besides ramp meter control, many other supply and demand side factors can also lead to travel time variation. For the purpose of this research, it is important to appropriately control for these other factors in the analysis.

Seasonal demand fluctuation It is well known that demand on freeways changes seasonally. The duration of the Mn/DOT ramp metering shut off experiment was eight weeks from the last week of October to the first week of December 2000. To minimize the impacts from seasonal demand change, comparable weeks in October to December 1999 were chosen in our analysis as days with ramp meter control.

Weather Although impacts of weather on freeway travel time have often been ignored in quantitative studies because it is discontinuous and difficult to plan or respond to, no evidence shows that weather can just be neglected. A study performed by the Mn/DOT TMC (traffic management center) in the late 1970s (Ries 1980) shows that precipitation, temperature, sky cover and wind speed all affect freeway capacity and hence travel time. In our study, days with more than 0.4 inches of hourly precipitation (rain, snow) in any PM peak period (14:30 to 19:00pm) are excluded.

Crashes It has been shown by many studies (and also in this ramp metering shut off experiment) that ramp metering can reduce freeways crashes. So, crashes are considered endogenous when comparing travel time variation with and without ramp metering. Days both with and without crashes are included. 


\section{MEASURING TRAVEL TIMES}

This section summarizes the calculation methodology required to measure travel times (and speeds) on entrance ramps, freeway segments, and O-D pairs on a highway with and without ramp meters.

The data collected for entrance ramps come in two types of paired data:

- Departure rate $\left(Q_{k}\right)$, arrival rate $\left(q_{k}\right)$ pair in each time interval $(k)$ obtained from volume detectors.

- Departure rate $\left(Q_{k}\right)$, queue length $\left(n_{k}\right)$ pair for each time interval obtained from volume detectors and periodic visual observation of queue length by remote cameras.

The second type data can be transformed to the first type by equation 2 :

$$
q_{k}=Q_{k}+n_{k}-n_{k-1}
$$

Where:

$q_{k} \quad$ the arrival rate in time interval $k$ (vehicles/hour);

$Q_{k}$ the departure rate in time interval $k$ (vehicles/hour);

$n_{k} \quad$ the queue length in time interval $k$ (number of vehicles).

Throughout the studied peak periods, all ramp upstream detectors have low occupancy readings and videotapes (at ramps without upstream detectors) do not show any queue spill-over effects to local connecting streets. This assures that the delays at on-ramps represent total delays caused by ramp meters.

Using the I/O queuing diagram shown in Figure 2, it is possible to find the total travel time every individual vehicle spends at ramps: $\left(t_{2}-t_{1}\right)$. This travel time contains two parts, the free flow travel time from ramp upstream detector to the departure detector and ramp delay. Since ramps are short in distance and the free flow travel time at ramps can be neglected, the time duration $\left(t_{2}-t_{1}\right)$ will be just called ramp delay for the remainder of this paper (A discussion on distinguishing "delay" and "waiting time in a queue" can be found in Lawson et al. (1997) and Lovell and Windover (1999) among others). The same method can be used to obtain arrival time, but assuming a uniform arrival at the back of the queue is not as accurate as assuming a uniform departure from the front of the metered queue, and is discussed more below.

The data are collected in 5 minutes intervals ( 5 minutes $=300$ seconds). So, the average time headway for time interval $\mathrm{k}$ equals $300 / Q_{k}(\mathrm{sec})$. Then the departure 
time of the first vehicle is $t_{1}$ which is equal to $h_{1}$. The departure time of the second vehicle is $t_{2}$ which is equal to $\left(h_{1}+h_{2}\right)$. As the time headway is accumulated, the departure time $\left(T_{v}\right)$ for every individual vehicle can be calculated. The arrival time $\left(t_{v}\right)$ can also be obtained by the same methods. Then the delay $\left(d_{v}\right)$ of every vehicle can be calculated by equation 3 :

$$
d_{v}=T_{v}-t_{v}
$$

Where:

$$
\begin{array}{ll}
t_{v} & \text { arrival time for vehicle } v ; \\
T_{v} & \text { departure time of vehicle } v \\
d_{v} & \text { delay of vehicle } v(\mathrm{sec})
\end{array}
$$

The departure rate within the window is still assumed to be uniform due to the presence of ramp meters. An assumption must be made about the arrival rate of vehicles at the back of the queue. Observed data is only available in five minute traffic counts. A uniform arrival rate would give a lower bound for delay estimation, a more reasonable assumption is to use an Poisson arrival process (the headways are exponentially distributed), which allows for bunching of vehicles. If the number of vehicles arriving at a queuing system has a Poisson distribution with a mean of $q_{k}$ customers per unit of time, the time between arrivals has an exponential distribution with a mean of $1 / q_{k}$. With the data collected by departure rate detectors, arrival rate detectors and queue length cameras at these ramps, the ramp delay for each vehicle and the average delay in each 5-minute time interval are obtained. The headway between vehicles is simulated using an exponential distribution 50 times, computing the delays using equation 3 , and then averaging the delay.

Freeway loop detectors provide the volume and occupancy information in 5 minutes intervals, useful for computing traffic flow on freeway segments. Based on these data, the space mean speeds in every time interval can be computed as in equation 4 :

$$
\bar{u}_{s, k_{1}}=\frac{100 Q_{k_{1}} L_{v}}{5280 \times 300 K_{k_{1}}}
$$

Where:
$\bar{u}_{s \mathrm{k}_{1}}$ space mean speed of detector 1 in time interval $k(\mathrm{~km} / \mathrm{sec})$;
$Q_{\mathrm{k} 1}$ volume of detector 1 in time interval $k$ (vehicles/hour);
$L_{v} \quad$ average vehicle length plus the length of the loop detector;
$K_{\mathrm{k} 1}$ time occupancy of the detector 1 in time interval $k(\%)$. 
Average vehicle length plus detector length, commonly known as the effective vehicle length is a crucial factor in estimating speed from single inductive loop detector flow and occupancy readings. Our average vehicle length estimates were taken from the Mn/DOT Traffic Management Center effective loop detector length calibration/normalization study. Because freeways have multiple lanes, there are more than one loop detectors at each station, there are multiple space mean speeds for one station derived from equation 4 (see figure 3). The weighted mean of all lanes will be used as the speed at each station, which is, e.g. for a two-lane freeway section:

$$
\bar{u}_{s, k}=\frac{K_{k_{1}} \bar{u}_{s, k_{1}}+K_{k_{2}} \bar{u}_{s, k_{2}}}{K_{k_{1}}+K_{k_{2}}}
$$

Assume that this speed is the average speed within this segment (that is, speeds within a segment are uniform). If there are no detectors in a segment, the speed of the nearest station will be assumed as the average speed in this segment (though this kind of situation rarely happens). Then the travel time of every time interval can be obtained:

$$
\tau_{k}=L / \bar{u}_{s, k}
$$

Where:

$\tau_{k} \quad$ travel time in time interval $k$,

$L \quad$ Length of the section.

Once the average delay on ramps and the average travel time in freeway segments in each time intervals are obtained, it is possible to build the travel time O-D matrices. However, this requires that the data be synchronized (that is we cannot simply add up the travel times of the entrance ramp and all freeway segments between an OD pair in time interval $k$ to obtain the total OD trips travel time in this interval, because a trip may take longer than 5 minutes and hence the travel time on one or more freeway segments for this trip may not be $\tau_{k}$ but $\tau_{k+1}$ or $\tau_{k+2}$ or ... ). Firstly, a database which records the delay and travel time data for each 5-minute period is built. Then the travel time for each O-D pair (from ramp $i$ to ramp $j$ ) will be calculated. Similarly, a delay matrix can be constructed. The trip travel time is calculated with equation 7 (see also figure 4):

$$
\tau_{i, j, k}=d_{r, k}+\tau_{i, k+x 1}+\tau_{i+1, k+x 2}+\ldots+\tau_{j-1, k+x(j-i)}
$$

Where:

$\tau_{i, j, k} \quad$ travel time from origin i to destination $j$ departing in time interval $k$; 
$d_{r, k} \quad$ delay on ramp $r$ in time interval $k$;

$\tau_{k+x 1}$ travel time in the freeway segment $\mathrm{i}$ in time interval $\left(k+x_{1}\right)$;

$x_{1}, x_{2}, \ldots, x_{j-i}$ : synchronization coefficient, $x$ is equal to the integer part of the result of the travel time from the origin to the beginning of this segment divided by the time interval (300sec).

With the method developed above, we are able to calculate travel times for all freeway OD pairs (where Os are entrance ramps and Ds are exit ramps) in 5-minute time intervals. To illustrate, we will use one trip group (trips with the same origin and destination) as an example in the following section and the computed travel times for this trip group can be summaries in one matrix (see table 1).

\section{TRAVEL TIME VARIATION}

There is considerable literature discussing measures for assessing travel time uncertainties (Asakura and Kashiwadani, 1991; Bell et al., 1999; Small, 1992). A recent review work on the subject was done by Bates et al. (2001). Given a series of travel times, several different summary measures can be derived indicating their deviation. Currently, two measures dominate the field: travel time reliability and travel time variation (or variability). Travel time reliability is defined as the probability that a trip can be made within a specific duration of time or alternatively, just a percentile of travel times (the former one sets a critical travel time while the latter sets a particular probability). Travel time variation is simply the standard deviation of travel times. Although theoretically those two summary statistics can be converted to each other if the distribution of the travel times are also known, its better to treat them as two different measures because at the current stage we are not clear about the distribution of travel times and how people perceive this distribution. Traditional travel demand theory prefers a measure that can be easily interpreted in terms of scheduling convenience. In evaluating value of travel uncertainty, a recent study (Lam and Small 2001) suggests the difference between the 90 percentile and the median of travel times.

From the freeway control perspective, a good measure of travel uncertainty must be calculable from routinely collected traffic data and can be easily incorporated into a benefit/cost analysis on control alternatives. The methodology we developed in the above section enables computation of both travel time reliability and variation from loop detector data. However, there is currently no conclusive answer to how travel uncertainty should be evaluated. It is noted by Bates et al. (2001) that both theory and recent empirical work suggests that the valuation of reducing travel uncertainty can be 
explained by travellers' scheduling consideration. But, since we know neither travellers' preferred schedule nor the flexibility of their actual schedule, it is impossible to aggregate scheduling convenience. Small et al. (1999) fit an econometric model which treats scheduling considerations implicitly using stated preference survey data and obtain an value of reliability in terms of reduction in travel time variation. This way, the difficulty of understanding travellers' true scheduling behaviour can be avoided. We will follow this line and evaluate the benefits of ramp metering on reducing travel time variation.

Here we look at two distinct types of travel time variation: inter-day and intra-day. For instance, inter-day travel time variation $V_{l, o f f}$ is the standard deviation of travel times of all trips with this OD (see table 1) starting between 14:30 and 14:35 pm from Oct. 25, 1999 to Dec. 5, 1999 excluding selected days noted in the Data section. The equation for calculating $V_{t}$ is simply given by:

$$
V_{t}=\operatorname{std}\left(\tau_{t, 1}, \tau_{t, 2}, \quad \ldots, \quad \tau_{t, n}\right)
$$

where:

$V_{t} \quad$ Inter-day travel time variation of trips starting at time interval $t$;

std() Standard deviation function;

$\tau_{t, n} \quad$ Travel time for trips starting at time interval $\mathrm{t}$ in day $n$.

On the other hand, $v_{1}$ is the intra-day travel time deviation of all PM peak trips with this OD in day 1 (Oct. 25, 1999). That is:

$$
v_{n}=\operatorname{std}\left(\tau_{1, n}, \tau_{2, n}, \quad \ldots, \quad \tau_{t, n}\right)
$$

where:

$v_{n} \quad$ Intra-day travel time variation of trips in day $n$;

std() Standard deviation function;

$\tau_{t, n} \quad$ Travel time for trips starting at time interval $t$ in day $n$.

Inter-day travel time variation affects long-term scheduling decisions on nondiscretionary tips (e.g. work trips) which occur daily. Intra-day travel time variation more likely influences discretionary trips (e.g. a shopping trip) or one-shot trips (e.g. a trip to visit a friend). However, these two types of variation may work interactively to shape travellers' overall perception of travel uncertainty. That perception arises from travellers' own experience, and determines their final scheduling decisions. Previous evaluations of travel reliability focus on work trips, hence their results more likely reflect the value of inter-day travel variation. 
For the purpose of comparing the metering-on case with the metering-off case, the inter-day variation difference $\left(D_{t}\right)$ is computed by subtracting metering-on values from metering-off values:

$$
D_{t}=V_{t, o f f}-V_{t, o n}
$$

For trips with this OD pair, we acquire a vector of inter-day travel time variation differences across different time intervals during the PM peak: $D_{1}, D_{2}, \ldots, D_{t}$. These results can be presented by a range-median diagram in which the range (lower/upper bound) and median value for this vector of inter-day travel time variation can be clearly identified (see figure 5 for an example of this graphical form).

Because of data processing techniques introduced in the above section, we couldn't get a perfect one-to-one match for intra-day travel time variation (i.e. the dates excluded from analysis due to weather etc. with ramp metering in 1999 may not be excluded without ramp metering in 2000 and vice versa). Rather than showing travel time variation differences between metering-on and metering-off cases directly (as equation 10 for inter-day travel time variation), the averages of travel time variation are computed separately for metering-on and metering-off cases. Then by comparing these two average values $(\bar{v})$, we ascertain whether ramp metering control reduces or increases intra-day travel time variation.

$$
\bar{v}=\operatorname{average}\left(v_{1}, v_{2}, \ldots, v_{n}\right)
$$

\section{RESULTS}

Inter-day travel time variation results for four freeways are shown graphically in Figure 6. It is obvious that for most OD pairs (103 out of 127 in which 26/45 OD pairs $\leq 5 \mathrm{kms}, 77 / 82$ OD pairs $>5 \mathrm{kms}$ ), inter-day travel time variability is reduced by implementation of ramp metering ( $\mathrm{t}$ tests of $\mathrm{V}_{\text {off }}-\mathrm{V}_{\text {on }}>0$ are statistically significant at level 0.01). Freeway peak hour travel reliability (including ramp delays) increases. The average reduction in inter-day travel time variation for short trips $(\leq 5 \mathrm{kms})$ is $0.17 \mathrm{~min}$ and for long trips $(>5 \mathrm{kms}) 1.91 \mathrm{~min}$. One can find that for extremely short trips $(\leq 3 \mathrm{kms})$, it is hard to say whether ramp meters improve travel time variations.

Figure 7 illustrates intra-day travel time variation results with two curves representing metering-on and metering-off cases. Although the intra-day travel time variation reductions caused by ramp meters differ by freeway segment, it is clear that ramp meters play a positive role in reducing intra-day travel time variation. Just as the inter- 
day results, intra-day travel time variation of long trips $(>5 \mathrm{kms})$ is reduced more significantly (on average $3.33 \mathrm{~min}$ ) than those of short trips ( $\leq 5 \mathrm{kms}, 0.01 \mathrm{~min})$.

Figure 8 compares the following three parameters of 36 OD trip pairs on TH 169 northbound: travel time saving per kilometer of travel; inter-day travel time variation reduction per kilometer of travel; ramp delay per kilometer of travel. Several points are worth to be noted from this limited comparison:

- For long trips, the Minnesota metering algorithm aiming at minimizing total travel time also significantly reduce congestion-related inter-day travel time variation, which can be seen at the right half of Figure 8 where both travel time saving and variation reduction become more and more constant.

- For shorter trips, since the weight of ramp delay become larger, both of the two objectives are not fulfilled satisfactorily and their relationships are not clear.

If day-to-day ramp delay is perfectly constant (i.e. the travel time variation with ramp metering is only due to freeway mainline travel time variation), the overall inter-day travel time variation could be additionally reduced by more than $50 \%$ for many OD pairs on the studied freeways (30/45 short trips, 15/82 long trips). Therefore, a metering algorithm able to achieve more stable ramp delay can significantly improve travel reliability, especially for short trips. Eliminating extremely long ramp delay is one practical improvement in this regard that can be made toward the existing or proposed metering algorithm in order to reduce ramp delay variability. Because of the non-linear nature of the value of ramp waiting time, this may also significantly reduce the perceived total travel time.

\section{VALUATION}

Black and Towriss (1993), Small (1995) and Small et al. (1999) estimated a "reliability ratio", defined as the ratio of cost of standard deviation to cost of mean travel time when scheduling costs are not separately considered (the ratio was estimated from a model where absolute travel time, travel time variation and monetary cost all appear as explanatory variables). They obtained consensus results of $0.7,1.27$ and 1.31 . Applying a 1.3 reliability ratio on $\$ 0.164 / \mathrm{min}(\$ 9.8 /$ hour $)$ value of time which is currently used by $\mathrm{Mn} / \mathrm{DOT}$, the value of per minute reduction in travel time variation would be $\$ 0.213 / \mathrm{min}$. The overall average inter-day travel time variation difference for all OD pairs in this study can be obtained, which is 1.5 minutes ${ }^{1}$. In other words, this means on average, implementation of ramp metering control reduces 1.5 minutes of inter-day standard deviation of travel time per trip. 
That would be $\$ 0.32$ savings per trip in monetary value $(1.5 \mathrm{~min} \times \$ 0.213 / \mathrm{min})$. This is still a conservative estimate because the benefits from reduced intra-day travel time variation are not taken into account. The total annual morning peak (6:00am to 9:00am) work trips can also be derived from detector counts ${ }^{2}$ and for year 2000, there are 103 million morning peak work trips. Therefore, the annual benefits brought by ramp meters in terms of reducing travel time variation for morning work trips alone would be $\$ 33.1$ million $(\$ 0.32$ /trips $\times 103$ million trips). Compared to the $\$ 2.6$ million annual ramp metering costs in the Twin Cities (Cambridge Systematics, Inc. 2001), this is definitely a huge benefit. Table 2 summarizes the valuation process.

\section{RECOMMANDATIONS AND DISCUSSION}

Ramp metering was designed to improve freeway traffic flow and safety. While it generally does both, it also has the affect of improving travel time reliability. This benefit should be captured in the analysis of ramp metering benefits. Further research is needed to develop a better way to monetize the value of reliability, however it is clearly positive.

Most of the existing and proposed ramp metering algorithms aim to minimize total travel time. Our results suggest that the benefits from reduced travel uncertainty outweigh the benefits from absolute travel time saving. Should we still aim to minimize absolute travel time and consider the benefits from reduced travel uncertainty as a positive outcome, or should we reframe our rationale for ramp metering? This is not an easy question because we do not know the inherent relationships between these two objectives, minimizing total travel time vs. minimizing travel time variation. They may be achieved simultaneously since a less congested freeway can reduce both absolute travel time and congestion-related travel time variation. But they may trade-off with each other. For instance, a metering algorithm which operates freeway at relatively high risk of breakdown could eventually save more travel time than another algorithm operating at low risk, but the latter control algorithm may achieve a higher travel reliability. Future studies should look at the theoretical relationships between those two objectives in more details. 
Levinson, D., Zhang , L. (2003) Travel Time Variability After A Shock: The Case Of The Twin Cities Ramp Meter Shut Off in The Network Reliability of Transport. Pergamon (editors Yasunori lida and Michael Bell)

\section{ACKNOWLEDGMENTS}

This research was part of the project Measuring the Equity and Efficiency of Ramp Meters funded by the Minnesota Department of Transportation. The authors want to thank Pat Otto, Dave Berg, John Hourdakis, James Aswegan, Rich Lau, John Bieniek, Atif Sheikh, Shantanu Das, and Frank Lilja for their assistance. The opinions and errors remain those of the authors.

\section{REFERENCE}

Asakura, Y. and M. Dashiwadani (1991). Road Network Reliability Caused by Daily Fluctuation of Traffic Flow. Proceedings of the $19^{\text {th }}$ PTRC Summer Annual Meeting, pp. 73-84

Banks, J.H. (1991). Two Capacity Phenomenon at Freeway Bottlenecks: A Basis for Ramp Metering? Transportation Research Record 1320, pp. 83-90

Bates, J., M. Dix and May A. (1987). Travel Time Variability and its Effect on Time of Day Choice for the Journey to Work. Transportation Planning Methods, Proceedings of Seminar C, PTRC, pp. 299-311

Bates, J., J. Polak, Jones P. and A. Cook (2001). The Valuation of Reliability for Personal Travel. Transportation Research Part E Vol. 37, pp. 191-229

Bell, M.G.H., C. Cassir, Iida, Y. and W.H.K. Lam (1999). A Sensitivity Approach to Reliability Assessment. Proceedings of the $14^{\text {th }}$ International Symposium on Transportation and Traffic Theory, July 20-23, pp. 283-300

Black, I.G. and J.G. Towriss (1993). Demand Effects of Travel Time Reliability. Center for Logistics and Transportation, Cranfield Institute of Technology

Bogenberger, K. and A. D. May (1999). Advanced Coordinated Traffic Responsive Ramp Metering Strategies. California PATH working paper UCB-ITS-PWP-99-19

Cambridge Systematics, Inc (2001) Twin Cities Ramp Metering Evaluation Report. Prepared for Minnesota Department of Transportation pursuant to laws 2000: Chapter 479, HF2891

Cassidy, M.J. and R.L. Bertini (1999). Some Traffic Features at Freeway Bottlenecks. Transportation Research Part B Vol. 33, pp. 25-42

Hall, F.L. and K. Agyemang-Duah (1991). Freeway Capacity Drop and the Definition of Capacity. Transportation Research Record 1320, pp. 91-98

Kang, S. and D. Gillen (1999). Assessing the Benefits and Costs of Intelligent

Transportation System: Ramp Meters. California PATH Research Report, UCB-ITS-PRR-99-19

Lam, T. and K. Small (2001). The Value of Time and Reliability: Measurement from a 
Levinson, D., Zhang , L. (2003) Travel Time Variability After A Shock: The Case Of The Twin Cities Ramp Meter Shut Off in The Network Reliability of Transport. Pergamon (editors Yasunori lida and Michael Bell)

Value Pricing Experiment. Transportation Research Part E Vol. 37, pp. 231251

Lawson, T., W., Lovell, David J. and C. Daganzo (1997). Using the Input-Output

Diagram to Determine the Spatial and Temporal Extents of a Queue Upstream of a Bottleneck. Transportation Research Record 1572

Lovell, D. J. and Windover, J. R. (1999). Analysing Freeway Traffic under Congestion: Traffic Dynamics Approach - Discussion by D.J. Lovell and J.R Windover. Journal of Transportation Engineering, July/August 1999

Levinson, D., L. Zhang, Das, S. and M. Sheikh (2001). Ramp Meters on Trial: the Case of Twin Cities Ramp Metering Shut Off. To be presented at TRB $81^{\text {st }}$ Annual Meeting, Washington, D.C., Jan. 13-17, 2002

Minnesota Department of Transportation (1996a). Traffic Management Program Overview: Twin Cities Metro Area. Report Number TMC07043-0196 February 1996.

Minnesota Department of Transportation (1996b). Freeway Operations Section Business Plan. Feb. 1996.

Minnesota Department of Transportation, Traffic Management Center (1998). Ramp Metering by Zone - The Minnesota Algorithm. Working Report

Minnesota Department of Transportation, Traffic Management Center (1999, 2000). All Detector Report.

Minnesota Department of Transportation (2000). website http://www.dot.state.mn.us Mn/DOT Metro Division, Traffic Management Center

Persaud, B.N. and V.F. Hurdle (1991). Freeway Capacity: Definition and Measurement Issues. Proceedings of the International Symposium of Highway Capacity, A.A. Balkema press, Germany, pp.289-307

Small, K. A. (1992). Urban Transport Economics. Fundamentals of Pure and Applied Economics series Vol. 51, Harwood Academic Publishers, New York.

Small, K, R. Noland, and P.M. Koskenoja (1995). Socio-economic Attributes and Impacts of Travel Reliability: A Stated Preference Approach. Draft PATH Report, MOU-117

Small, K., R. Noland, Chu, X. and D. Lewis (1999). Variation of Travel-Time Savings and Predictability in Congested Conditions for Highway User-Cost Estimation. NCHRP Report 431

Ries, G. (1980). Impact of Weather on Freeway Capacity. Mn/DOT Metro Division, Traffic Management Center research project report (unpublished) 
Levinson, D., Zhang , L. (2003) Travel Time Variability After A Shock: The Case Of The Twin Cities Ramp Meter Shut Off in The Network Reliability of Transport. Pergamon (editors Yasunori lida and Michael Bell)

\section{TABLES AND FIGURES}

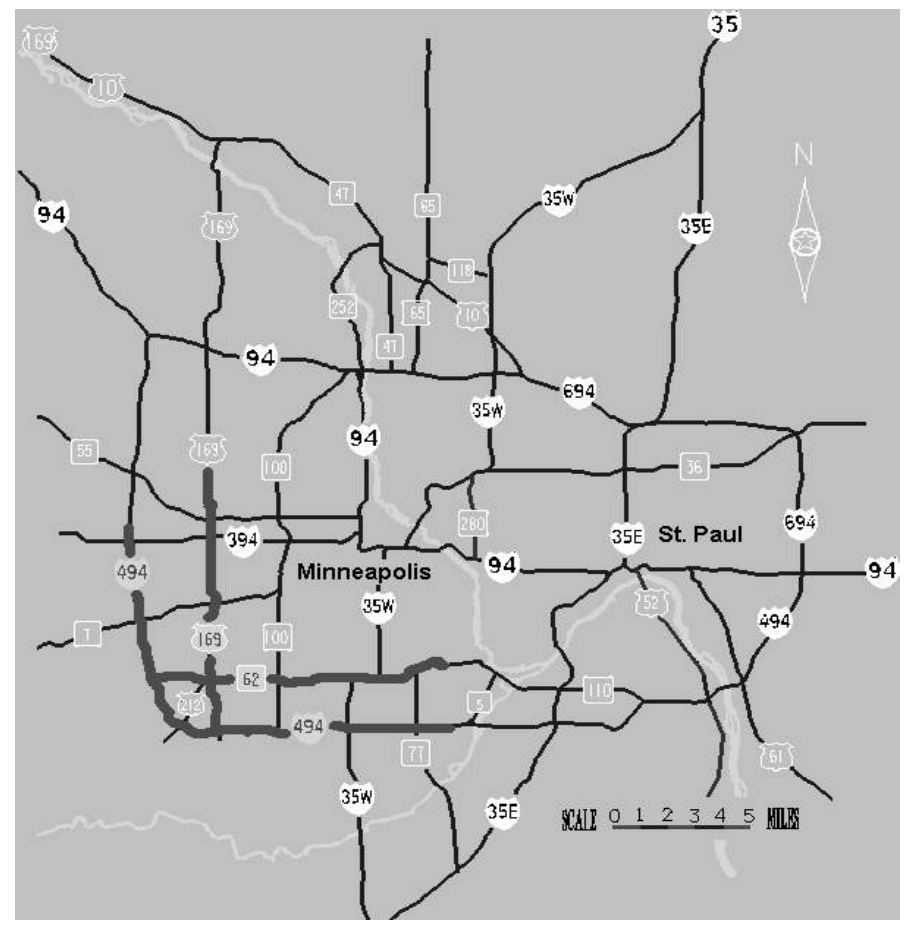

Figure 1 Freeway segment location map

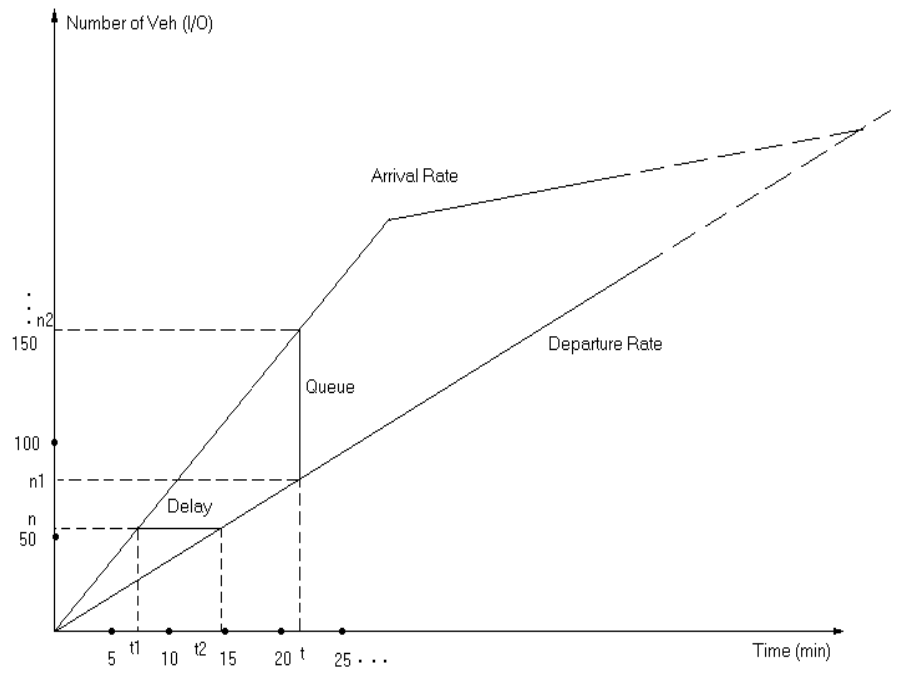

Figure 2 Queuing diagram 
Levinson, D., Zhang , L. (2003) Travel Time Variability After A Shock: The Case Of The Twin Cities Ramp Meter Shut Off in The Network Reliability of Transport. Pergamon (editors Yasunori lida and Michael Bell)

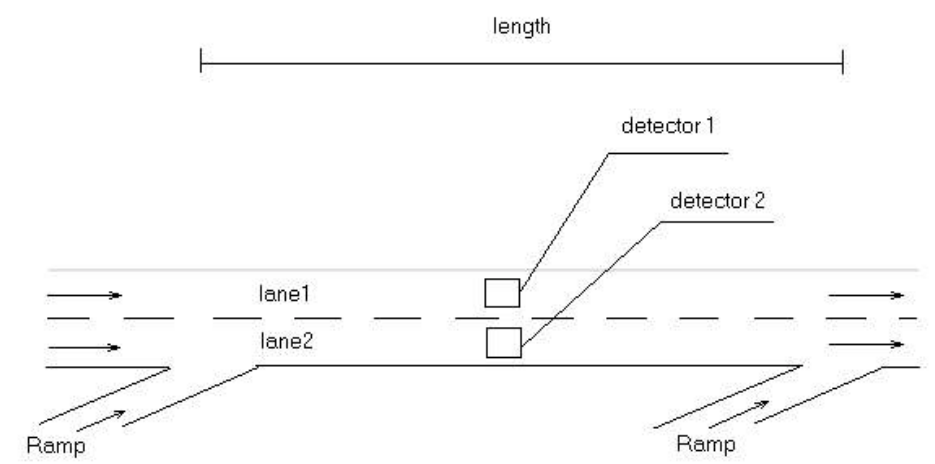

Figure 3 Illustration of freeway detectors

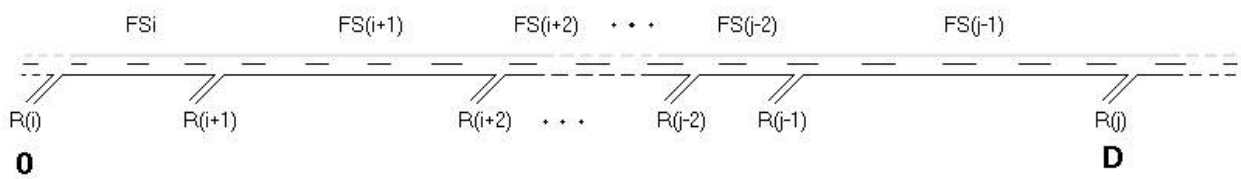

\section{Figure 4 Building trip travel times}

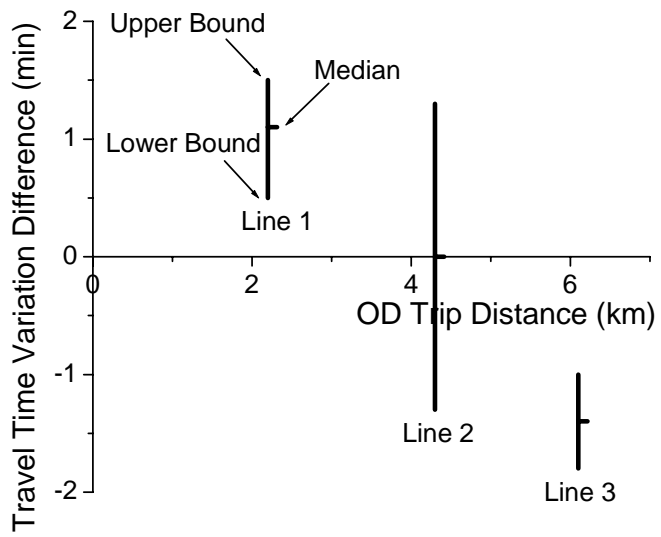

Three vertical lines in Figure 5 graphically describe three possible results of the range and median of a vector of inter-day travel time variation differences (metering off value - metering on value). If in one time interval, ramp meter control decreases (increases) OD travel time variation, this would be represented by line 1 (line 3 ). If ramp meter control doesn't affect travel time variation at all, line 2 is the case. From the $\mathrm{x}$-axis, one can read the trip OD distance (total travel distance).

Figure 5 Possible results of inter-day travel time variation difference 
Levinson, D., Zhang , L. (2003) Travel Time Variability After A Shock: The Case Of The Twin Cities Ramp Meter Shut Off in The Network Reliability of Transport. Pergamon (editors Yasunori lida and Michael Bell)

TH169 NB 36 OD Pairs

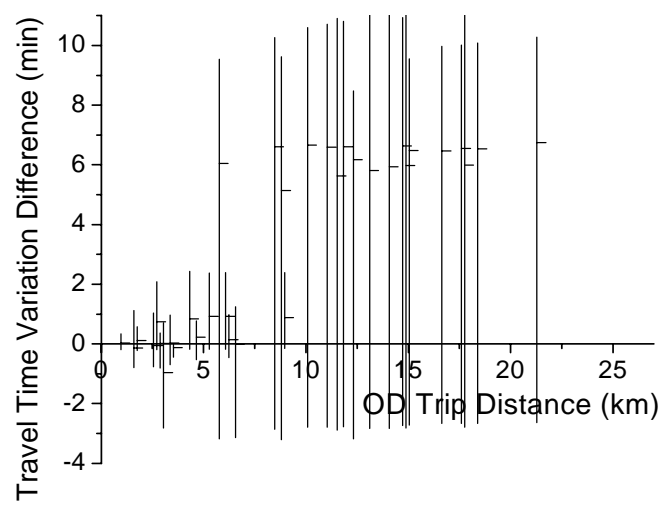

TH169 NB 36 OD Pairs

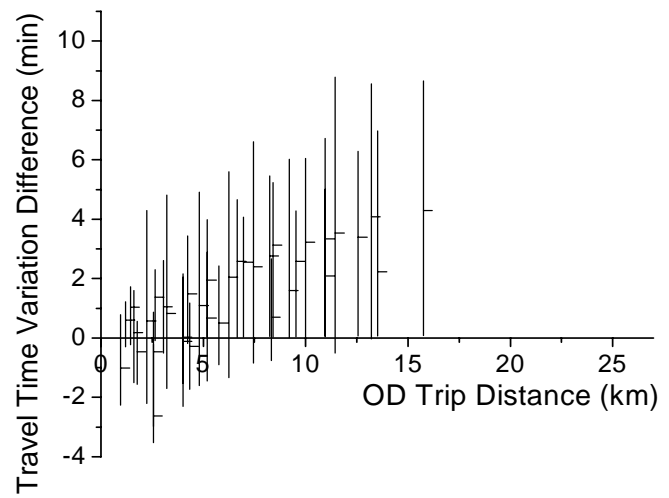

I494 WB\&NB 25 OD Pairs

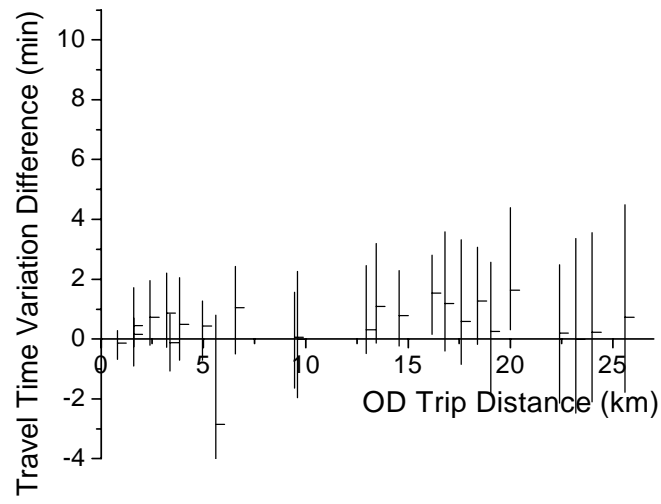

TH62 WB 32 OD Pairs

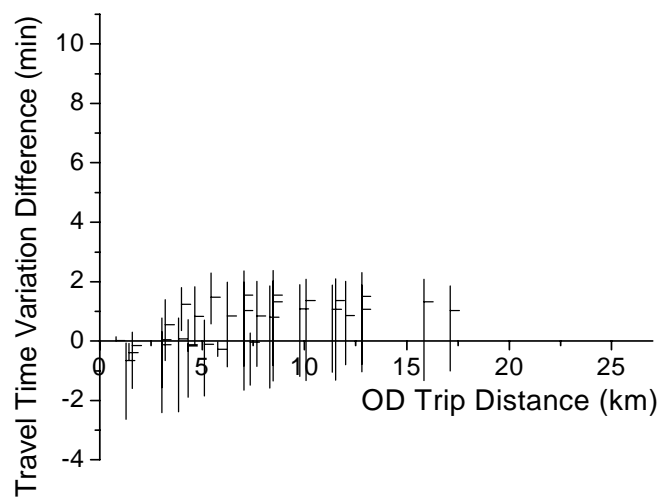

Figure 6 Inter-day travel time variation difference of each freeway without ramp meters - with ramp meters $\left(V_{\text {off }}-V_{\text {on }}\right)$ 
Levinson, D., Zhang , L. (2003) Travel Time Variability After A Shock: The Case Of The Twin Cities Ramp Meter Shut Off in The Network Reliability of Transport. Pergamon (editors Yasunori lida and Michael Bell)

TH169 NB 36 OD Pairs

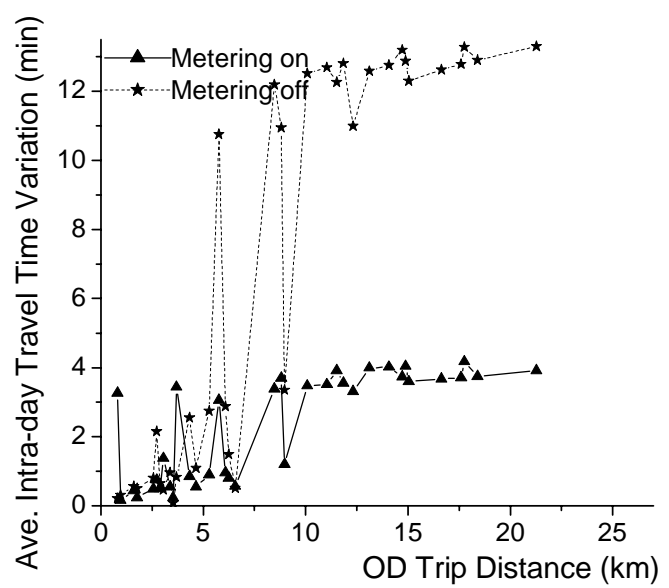

TH169 NB 36 OD Pairs

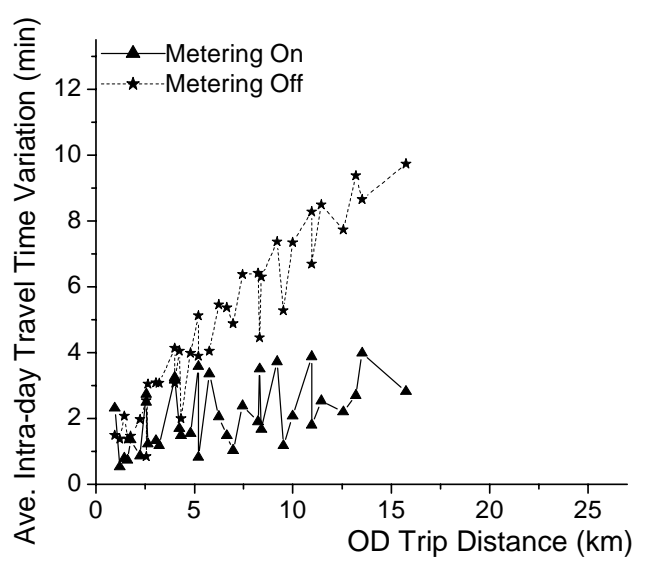

I494 WB\&NB 25 OD Pairs

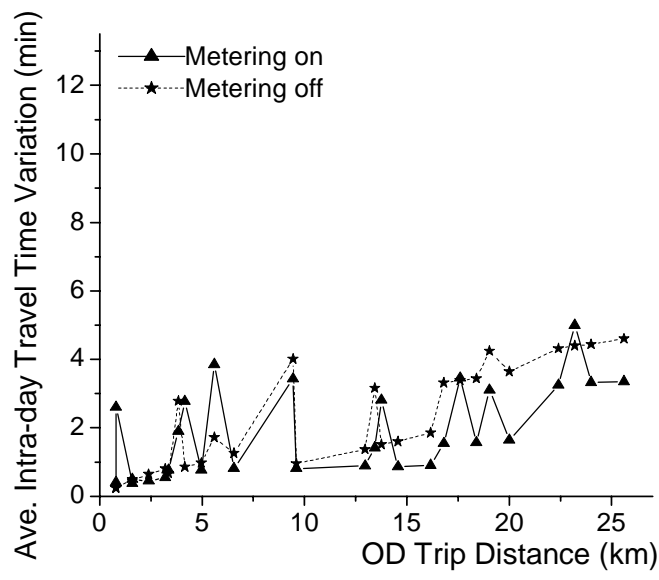

TH62 WB 32 OD Pairs

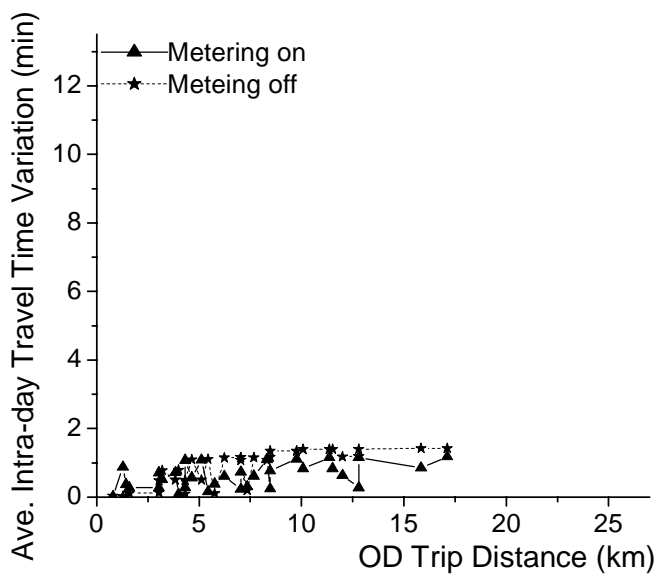

Figure 7 Intra-day travel time variation: with/without ramp metering control 
Levinson, D., Zhang , L. (2003) Travel Time Variability After A Shock: The Case Of The Twin Cities Ramp Meter Shut Off in The Network Reliability of Transport. Pergamon (editors Yasunori lida and Michael Bell)

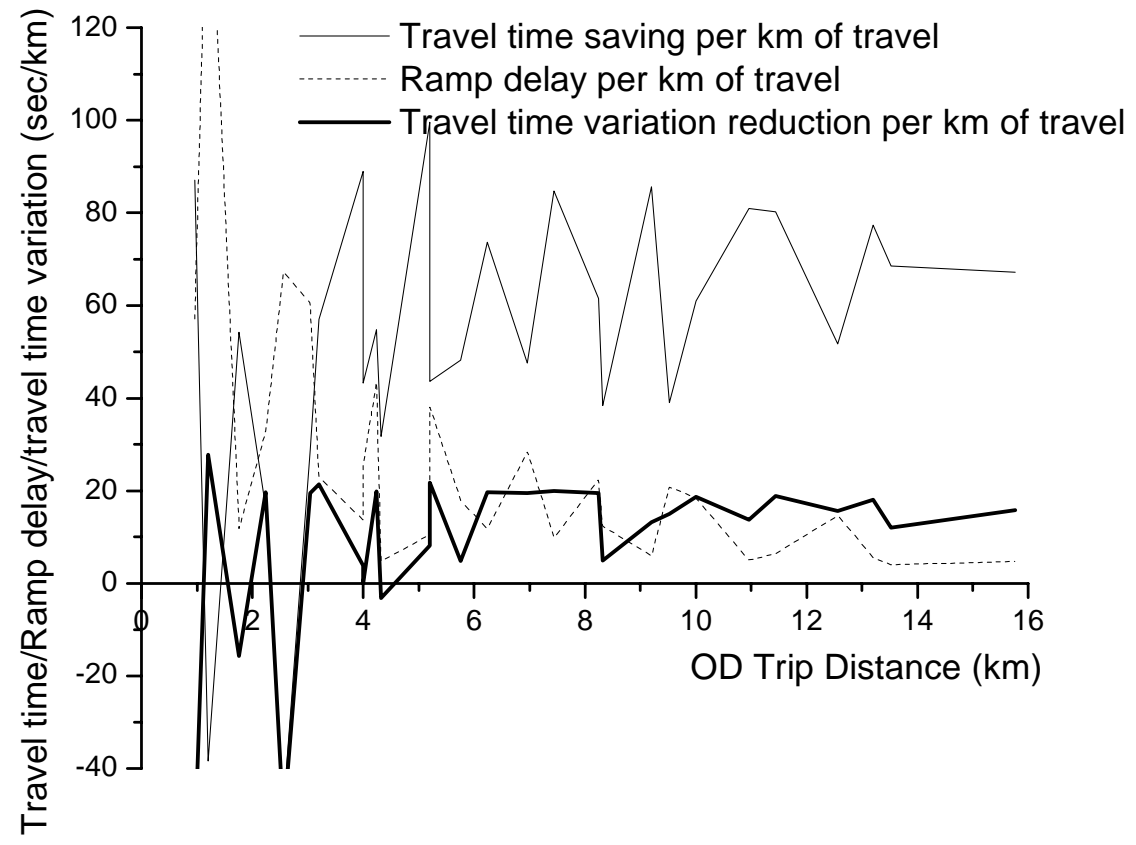

Figure 8 Travel time saving/ramp delay/inter-day travel time variation reduction Per kilometer of travel with ramp metering 
Levinson, D., Zhang , L. (2003) Travel Time Variability After A Shock: The Case Of The Twin Cities Ramp Meter Shut Off in The Network Reliability of Transport. Pergamon (editors Yasunori lida and Michael Bell)

\section{Table 1 Travel time matrix (days $\times$ time intervals) for one OD pair}

\begin{tabular}{|c|c|c|c|c|c|c|}
\hline $\begin{array}{l}\text { Time } \\
\text { Interval } \\
\qquad 1999 \text { On } \\
2000 \text { Off }\end{array}$ & $\begin{array}{l}\text { Day } 1 \\
(10 / 25) \\
(10 / 23)\end{array}$ & $\begin{array}{l}\text { Day } 2 \\
(10 / 26) \\
(10 / 24)\end{array}$ & $\ldots$ & $\begin{array}{l}\text { Day n -1 } \\
(12 / 04) \\
(12 / 02)\end{array}$ & $\begin{array}{l}\text { Day n } \\
(12 / 05) \\
(12 / 03)\end{array}$ & $\begin{array}{l}\text { Inter-Day } \\
\text { Travel } \\
\text { Time } \\
\text { Variation }\end{array}$ \\
\hline$(14: 30)$ & $\tau_{11}$ & $\tau_{12}$ & $\ldots$ & $\tau_{1(n-1)}$ & $\tau_{l n}$ & $V_{1, \text { on/off }}$ \\
\hline$(14: 35)$ & $\tau_{21}$ & $\tau_{22}$ & $\ldots$ & $\tau_{2(n-1)}$ & $\tau_{2 n}$ & $V_{2, \text { on/off }}$ \\
\hline$(14: 40)$ & $\tau_{31}$ & $\tau_{32}$ & $\ldots$ & $\tau_{3(n-1)}$ & $\tau_{3 n}$ & $V_{3, \text { on/off }}$ \\
\hline $\begin{array}{l}\cdots \\
t-1(18: 25)\end{array}$ & $\begin{array}{l}\ldots \\
\tau_{(t-1) 1}\end{array}$ & $\tau_{(t-1) 2}$ & $\begin{array}{l}\ldots \\
\ldots\end{array}$ & $\begin{array}{l}\ldots \\
\tau_{(t-1)(n-1)}\end{array}$ & 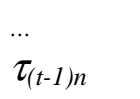 & $\dddot{V}_{t-1, \text { on/off }}$ \\
\hline $\mathrm{t} \quad(18: 30)$ & $\tau_{t 1}$ & $\tau_{t 2}$ & $\ldots$ & $\tau_{t(n-1)}$ & $\tau_{t n}$ & $V_{t, \text { on/off }}$ \\
\hline $\begin{array}{l}\text { Intra-Day } \\
\text { Travel Time } \\
\text { Variation }\end{array}$ & $v_{1, \text { on/off }}$ & $v_{2, \text { on/off }}$ & $\ldots$ & $v_{(n-1), \text { on/off }}$ & $v_{n, \text { on/off }}$ & $\bar{v}_{\text {on/off }}$ \\
\hline \multicolumn{4}{|c|}{$\begin{array}{l}\text { On: with ramp metering control; } \\
\text { V: inter-day travel time variability; }\end{array}$} & \multicolumn{3}{|c|}{$\begin{array}{l}\text { Off: without ramp metering control; } \\
\text { v: intra-day travel time variability; }\end{array}$} \\
\hline
\end{tabular}

Table 2 Annual benefits from travel time variation reduction

\begin{tabular}{lr}
\hline Value of travel time (VOT) & $\$ 0.164 / \mathrm{min}$ \\
Reliability Ratio (RR) & 1.3 \\
Value of travel time variation (RR*VOT) & $\$ 0.213 / \mathrm{min}^{(1)}$ \\
Inter-day travel time variation reduction per trip & $1.5 \mathrm{~min}^{(2)}$ \\
Annual total number of home-to-work trips & 103 million \\
Annual Benefits $(1) *(2) *(3)$ & $\$ 33.1$ million \\
\hline
\end{tabular}

\section{ENDNOTES}

\footnotetext{
${ }^{1}$ This average is computed by assuming that all OD pairs have the same number of trips. This may not be a bad assumption because we are work on a total number of 105 OD pairs and errors may be cancelled out to a large extent. Also the average OD distance for all OD pairs are $8.4 \mathrm{~km}$ which should be close to the actual average freeway travel distance.

${ }^{2}$ The basic idea is that we sum up morning peak (6:00am to 9:00am) volume across all boundary detectors of the managed freeway system (freeways controlled by ramp metering). The selected detectors are either located at mainline entrance stations or entrance ramps (freeway to freeway entrance ramps are excluded). In case that a loop detector was not functioning, we look for substitutive detectors (e.g. if an entrance ramp detector was not functioning but both mainline detection stations immediately before and after this entrance ramp worked well, these mainline detectors can be the substitutes for this entrance ramp detector). We also assume that $80 \%$ of the morning commutes are work trips.
} 